\title{
Effect of Snow Stereology on Millimeter Wave Extinction
}

\author{
Gary Koh and Robert E. Davis \\ US Army Cold Regions Research and Engineering Laboratory \\ 72 Lyme Road \\ Hanover, NH 03755-1290 USA \\ T: 603.646.4282 F: 603.646.4644 EMail: gkoh@hanover-crrel.army.mil
}

\begin{abstract}
A network analyzer based system was used to measure the extinction coefficient of various snow types at 26.5 to $40 \mathrm{GHz}$ under controlled laboratory conditions. The snow samples were prepared using sieved snow so that the physical properties of the snow could be extensively characterized. By using sieved snow, it was possible to vary and to measure the size distribution of the disaggregated ice particles making up the snow sample. In addition, snow stereology measurements were made to obtain the microstructural properties of the snow samples. These results were then used to identify the key snow pack parameters that are required to determine the extinction behavior of a snow pack at the radar frequencies.
\end{abstract}

\section{INTRODUCTION}

Microwave and millimeter wave interactions with a snow pack are of considerable interest for radar remote sensing applications in a polar environment. A snow pack consists of interconnected ice particles where the effects of rough surface scattering and volume scattering need to be understood in order to predict or to interpret radar signatures from a snow-covered terrain. If a snow pack is dry, much of the radar signal incident on the snow surface can penetrate into the snow so that scattering from features below the snow surface becomes important. The extent of the subsurface scattering contribution to a radar signature depends largely on the extinction properties of snow.

The extinction behavior of a snow pack at the radar frequencies has been difficult to investigate due to the complex structure of a snow pack. The results from previous snow extinction measurements (Hallikainen 1987; Koh 1994) suggest that snow microstructure need to be characterized before one can accurately predict the extinction properties of a snow pack. For snow extinction studies a potentially useful technique for characterizing the detailed structure of a snow pack is snow stereology (Davis et al 1987; Davis and Dozier 1989; Shi et al 1993).

In this paper, we present snow extinction measurements that were conducted under controlled laboratory conditions in conjunction with detailed characterization of snow. A network analyzer operating at the $\mathrm{Ka}$ band was used to measure the extinction coefficient of laboratory prepared snow samples. The size distribution of the disaggregated snow particles which were used to prepare the snow samples was measured. Stereological determination of the snow samples was also obtained. These results were used to identify the important snow pack properties required for snow extinction studies.

\section{EXPERIMENT DESCRIPTION}

\section{Snow Preparation and Characterization}

Sieved snow was used to prepare spatially homogeneous samples that were of sufficient thickness to cause measurable extinction. A desired snow type was first gathered in large insulated containers and brought into a coldroom whose temperature was set at $-2.5^{\circ} \mathrm{C}$. The snow was then sifted using a $2.3-\mathrm{mm}$ aperture sieve. After passing through the sieve, the snow fell approximately $30 \mathrm{~cm}$ before accumulating in a sample holder that consisted of a plexigalls tube $(30 \mathrm{~cm}$ in diameter and $15 \mathrm{~cm}$ in depth) with a flat metal base. Six different snow types were used to prepare the samples. For each snow type four samples (density was varied) were prepared.

In order to measure the sizes and shapes of the disaggregated snow particles, approximately 50 snow particles were intercepted as they fell after being sieved on a $10 \times 13 \mathrm{~cm}$ glass plate coated with a Formvar replicating solution (Schaeffer, 1941). These replicated snow particles were later photographed and digitized. Image analysis software was used to measure size- and shaperelated snow parameters. The projected area of each snow particle was measured and then converted to equivalent radius (radius of circle with equivalent area). The histograms of the equivalent radius for the six different snow types are illustrated in Figure 1.

Stereological analysis of the snow samples were also conducted in hopes of identifying additional snow parameters that may be useful for investigating the extinction behavior of a snow pack. Representative sections of the snow samples were cut and placed in a container and saturated with supercooled dimethyl phthalate (Perla, 1982) to fill the pore space. The samples were frozen, which resulted in solid blocks for machining. Each block was cut in two, shaved on microtome and polished. The specimen was left to sublimate to remove the ice from the ice grain profiles exposed to the cut. Photocopy toner was then applied to the etched surface to provide contrast between the etch pits and the pore filler surface.

Digital images were framed-grabbed directly from the prepared section cuts using a monochrome CCD camera and a Zeiss Tesovar lens. Standard stereological measurements were carried out on each image. The mean ice and pore intercept lengths and the volume-to-surface ratio were obtained. The stereological parameters for all the snow sample are illustrated in Figure 2. 

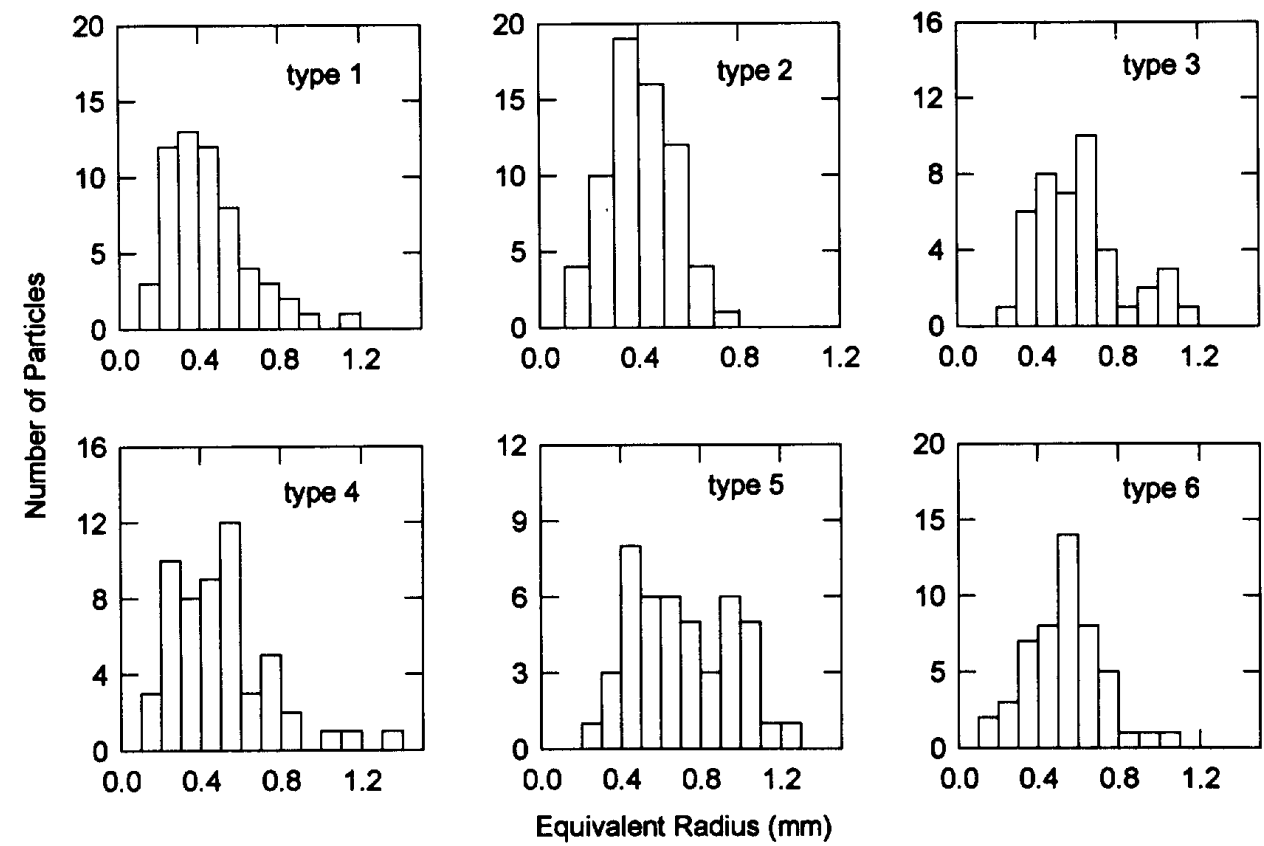

Figure 1. Distribution of equivalent radius for six different snow types.
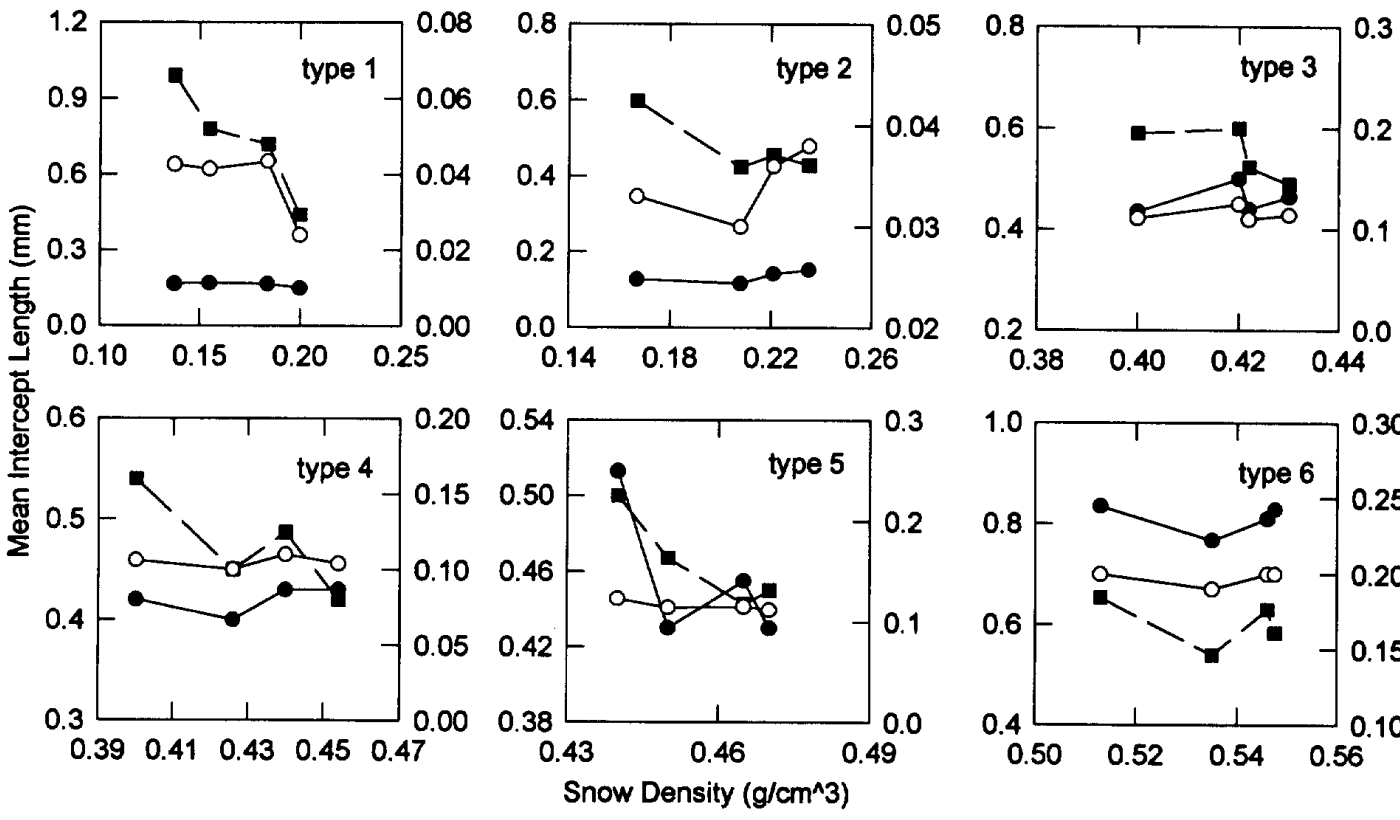

0.3

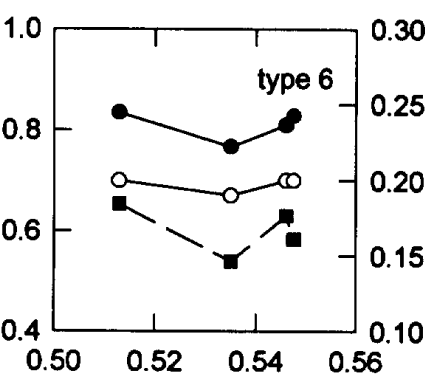

Figure 2. Stereological parameters for six snow types. Filled circles and squares represent mean ice intercept and mean pore intercept lengths, respectively. Open circles represent volume-to-surface ratio. 


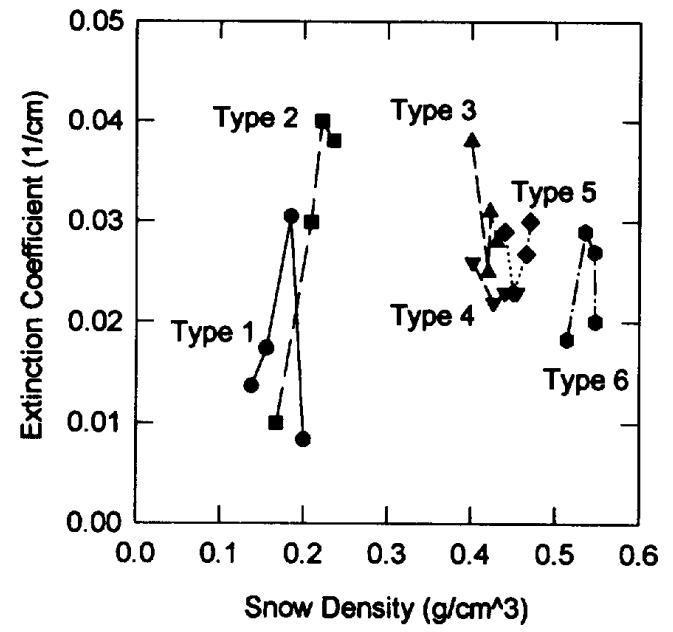

Figure 3. Extinction coefficient of snow samples. The lines connect samples of different densities prepared from the same snow type.

\section{Extinction Measurement}

The extinction coefficient measurements were obtained using an HP8510B network analyzer in a single port reflectometer arrangement. The HP8510B measured the signals reflected from the snow samples in the frequency domain. An inverse Fourier transform was used to convert the band-limited frequency domain data into narrow pulses in the time domain so that pulse reflection as a function of time (location) was obtained. The extinction coefficient was obtained from the amplitudes of the pulses reflected from the air-snow interface and the snow-metal boundary. The results of the extinction measurements are illustrated in Figure 3. The lines connect the snow samples of different densities which were prepared from the same snow type. Significant variations in extinction can occur for a given snow type with slightly different densities.

\section{RESULTS AND CONCLUSION}

The overall extinction trend in snow can be estimated using a simple modification to the independent scattering assumptions (Koh, 1994). These results are illustrated in Figure 4 where the average extinction for a given snow type are compared with those calculated based on the mean size of the disaggregated snow particles (for illustrative purposes mean size of $0.5 \mathrm{~mm}$ was used to calculate the extinction coefficient) and the snow density. However, the variations in the extinction observed for a given snow type cannot be explained using such simplifying assumptions. It was hoped that the stereological analysis might yield information that could account for the extinction variations observed within a given snow type.

Comparisons of Figures 2 and 3 did not provide an obvious correlation between the extinction trend and stereological parameters. It is seen that for a given snow type the changes in density are accompanied by changes in the stereological parameters. The effect of these stereological changes on the extinction properties of a snow pack will require further investigations.

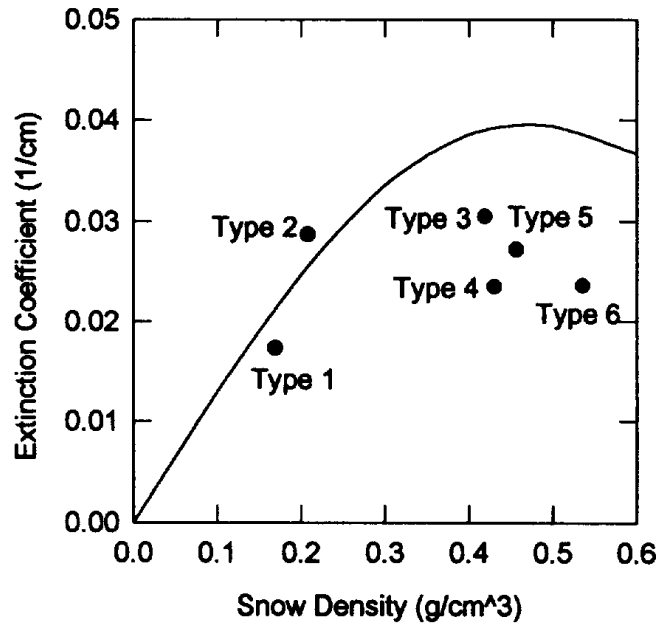

Figure 4. Comparison of measured extinction coefficients with those calculated based on modified independent scattering assumptions.

\section{REFERENCES}

Davis, R.E. and J. Dozier. "Stereological characterization of dry alpine snow for microwave remote sensing." Advances in Space Research, vol 9, 245-251, 1989.

Davis, R.E., J. Dozier and A.T.C. Chang. "Snow property meaurements correlative to microwave emission at $35 \mathrm{GHz}$." IEEE Trans. Geosci. Remote Sensing, vol GE-25, 751-757, 1987.

Halikainen, M.,F.T. Ulaby and T.E. van Deventer. "Extinction behavior of dry snow in the 18- to 90-GHz range." IEEE Trans. Geosci. Remote Sensing, vol GE-25, 737-745, 1987.

Koh, G. "Applicability of dense medium extinction theory for snow cover." submitted to IEEE Trans. Geasci. Remote Sensing.

Perla, R. "Preparation of section planes in snow specimens" $J$. Glacio., 14, 467-477, 1982.

Schaeffer, V.J. "A method for making snowflake replicas" Science, 93, 239-240, 1941.

Shi, J., R.E.Davis and J.Dozier. "Stereological determination of dry-snow parameters for discrete-scatterer microwave modeling." Annals of Glaciology, vol 17, 295-299, 1993. 